\title{
The effect of D-amphetamine on visual vigilance performance in the squirrel monkey
}

\author{
DANIEL F. RICE and WALTER ISAAC \\ University of Georgia, Athens, Georgia
}

(Bradford N. Bunnell, Sponsor)

\begin{abstract}
Three male squirrel monkeys were tested for their ability to make detections on a visual vigilance task, using a within-subjects repeated measures design. Each animal was tested with four doses of D-amphetamine; $0.0,0.1,0.2$, and $0.4 \mathrm{mg} / \mathrm{kg}$, under both noise and quiet conditions. Damphetamine decreased the frequency of detections as dose was increased. This effect occurred in the quiet but not the noise condition. Detection rate was lower and less consistent in the noise condition than in the quiet condition. The results are considered in terms of (1) a depressing effect of amphetamine on central nervous system arousal, and (2) the disrupting effect of white noise on a visual vigilance task.
\end{abstract}

Very few studies have been done with nonhuman primates on a visual vigilance task. The available literature on white noise and visual vigilance performance in humans indicates that a more complex task, or one requiring attentional flexibility, is not performed as efficiently under white noise as in quiet conditions (Jerison, 1957). In general, white noise may impair, improve, or have no effect on visual vigilance performance in humans. When white noise impairs performance, the deficit may be attributed to a distraction of visual attention (Davies \& Tune, 1969). In the present study, white noise was introduced as a potentially arousing stimulus that might interact with D-amphetamine and either facilitate or inhibit vigilance performance.

Amphetamine is classified, pharmacologically, as a central nervous system (CNS) stimulant (Gilman, Goodman, Rall, \& Murad, 1985). Amphetamine acts on subcortical nuclei in the forebrain and the brainstem reticular formation (see Groves \& Tepper, 1983, for a review). The reticular activating system regulates cortical arousal in response to incoming sensory information from all sensory modalities (Lindsley, 1958). French (1960) cited a number of experiments in which it was demonstrated that amphetamine facilitates neural transmission in the reticular activating system. Isaac (1971) has shown that amphetamine alters visual neural transmission at the pontinemesencephalic reticular formation in the rat.

Despite the general classification of amphetamine as a CNS stimulant, Isaac and Troelstrup (1969) have shown that $\mathrm{D}$-amphetamine decreases motor activity in the diur-

This research was reported at the 1989 SEPA convention in Washington, DC. This paper was taken from D. F. Rice's MS thesis under the direction of Walter Isaac, who died before its completion. Requests for reprints should be addressed to D. F. Rice, Department of Psychology, University of Georgia, Athens, GA 30602. nal squirrel monkey, but that it increases activity in the nocturnal owl monkey. Delay and Isaac (1980) found a decrease of detections on an auditory vigilance task in squirrel monkeys as doses of $\mathrm{D}$-amphetamine were increased. These experiments, and other similar work, indicate that amphetamine has different effects on diurnal and nocturnal animals and that it is not simply a general CNS stimulant.

Vigilance may be defined as a readiness to respond to an effective stimulus (Davies \& Tune, 1969). When vigilance is measured on a specific task, the rate of detection of a recurring brief signal is usually considered to be its definitive index. Essentially, when vigilance is low, correct detections of the signal are low, and when vigilance is high, correct detections are increased $(\mathrm{Da}-$ vies \& Tune). Hebb (1955) has suggested that the term vigilance is very similar to the concept of a constant, underlying arousal level that defines an animal's ability to respond to its environment. Taylor (1969) has suggested that the reticular activating system mediates states of vigilance in the animal.

This experiment was conducted to investigate the effect of D-amphetamine on a task requiring a constant level of CNS arousal. Isaac (1971) has shown that amphetamine alters visual information sent to the brainstem reticular formation by disrupting superior colliculus neurotransmission. Reduced illumination is an excitatory stimulus for nocturnal animals. The nocturnal rat is more active and more vigilant under amphetamine (Squire \& Golden, 1988). Diurnal animals, on the other hand, might be expected to be less aroused and active when visual stimulation is reduced. By testing diurnal squirrel monkeys under constant light conditions in a task requiring a sustained level of arousal, we investigated variations in arousal due to $\mathrm{D}$-amphetamine.

Amphetamine lowers activity in squirrel monkeys (Isaac $\&$ Trolestrup, 1969). It was considered likely that because 
the subjects in this study would be relatively inactive, they might be more attentive under amphetamine to the stationary recurring light signal. In other words, detections might improve because of amphetamine's inhibiting effect on motor activity. The introduction of white noise under these circumstances might either distract the animal and disrupt performance of the task or interact with amphetamine to increase arousal and attention and thereby improve performance.

\section{METHOD}

\section{Subjects}

Three male Saimiri-2 Saimiri sciureus and 1 Saimiri boliviensis (Hershkovitz, 1984)-were used as subjects. The animals were housed in their home cages in a colony room maintained on a 12:12-h light:dark cycle with lights on at $0800 \mathrm{~h}$. Water was available ad lib in the home cages. The subjects were fed after the testing session each day, at approximately $1800 \mathrm{~h}$.

\begin{abstract}
Apparatus
The subjects were transported individually from their home cages to the test chamber in a metal carrying cage that measured $40.6 \mathrm{~cm}$ long, $25.4 \mathrm{~cm}$ wide, and $25.4 \mathrm{~cm}$ high. The carrying cage was placed in a sound-attenuated chamber with the following inside dimensions: $71.1 \mathrm{~cm}$ deep, $71.1 \mathrm{~cm}$ wide, and $53.3 \mathrm{~cm}$ high. A Masonite board, painted flat white, was substituted for one door of the carrying cage after it was placed in the testing chamber. The response lever was mounted on a clear plastic panel on this board, and extended $3.5 \mathrm{~cm}$ into the carrying cage, $7.5 \mathrm{~cm}$ above the cage floor. The response lever also served as the reinforcement site. The lever, which had a shallow indentation, was connected to a solenoid valve by plastic tubing; the reinforcer, sugarsweetened Hawaiian Punch, was delivered to the indentation through the plastic tubing.

The signal light, a high-brightness, 20-mA LED, was located just behind the lever in the clear plastic panel. This light signaled the onset of the reinforcement trial. Ambient light, provided by a fluorescent light mounted in the ceiling panel of the chamber, was equivalent to $10 \mathrm{fc}$ at the floor of the chamber. Ambient noise, produced by a ventilation fan, was $68 \mathrm{~dB}$ (C scale). A white-noise generator provided $80 \mathrm{~dB}$ (C scale) of sound to a speaker located inside the chamber. Programming
\end{abstract} circuitry was located in a separate room.

\section{Procedure}

In preliminary training, the animals were trained to a criterion of a minimum of 15 of 24 signal detections on 3 consecutive days ( 1 detection of 24 signals would be chance performance). When this criterion was reached, drug administration was begun. Four doses of Damphetamine were administered: $0.0,0.1,0.2$, and $0.4 \mathrm{mg} / \mathrm{kg}$. These doses, adjusted for body weight, approximated and exceeded the doses used in treating hyperactive children. The dose sequence was determined by a Latin square design. The animals were given the appropriate dose of D-amphetamine, orally, in approximately $3 \mathrm{cc}$ of sweetened Hawaiian Punch 20 min prior to being placed in the chamber. The effect of each dose was evaluated under two noise conditions, with constant low ambient illumination in both. The high- and low-noise conditions were presented on alternate days. There were three replications. Each replication consisted of eight test sessions in which each of the four doses was presented once under both the quiet and the noise conditions.

The duration of one trial was $5 \mathrm{sec}$. The light signal came on for $2 \mathrm{sec}$. Reinforcement remained available for an additional $3 \mathrm{sec}$. A correct response occurred when the monkey first pushed the lever in response to the signal during the 5 -sec trial; this detection produced $.10 \mathrm{cc}$ of the reinforcer. The average time between trials was $2.4 \mathrm{~min}$, with a range of $1 \mathrm{~min}$ to $4 \mathrm{~min} 20 \mathrm{sec}$. There were 24 trials during the 58 -min experimental session. Each session was divided into four 14.5-min intervals, and correct responses during each interval were recorded. False alarms were recorded when the lever was pushed at any time other than during the 5-sec trial when reinforcement was available. A response made during the $10 \mathrm{sec}$ prior to a trial delayed that trial $10 \mathrm{sec}$. The delay was intended to reduce the number of false alarms.

\section{RESULTS}

The total number of correct responses by the 3 subjects was analyzed with a within-subjects five-factor analysis of variance. The main factors were replications (3), dose (4), noise-quiet (2), intervals (4), and subjects (3). A pooled error term was used. The analysis revealed a significant effect of dose $[F(3,190)=27.80, p<.005]$. Figure 1 illustrates the decrease in detection rate as the dose of D-amphetamine was increased. The effect of noise on detection rate was significant $[F(1,190)=44.26$, $p<.005]$. Figure 2 shows the low and inconsistent detection rate in the noise condition compared with that in the quiet condition. Detections decreased over the hourlong test session, and the change in detections by interval was significant $[F(3,190)=3.46, p<.05]$. Detections also decreased with replications $[F(2,190)=4.26$, $p<.05]$. The three-way interaction between dose, noisequiet, and replication was significant $[F(6,190)=3.18$, $p<.01]$. Figure 2 shows the decrease in detection rate across replications as a function of dose and noise. A separate analysis revealed that false alarms decreased as dose was increased $[F(3,71)=7.7022, p<.005]$. Noise also decreased false alarms $[F(1,71)=9.081, p<.005]$.

\section{DISCUSSION}

D-Amphetamine, at the approximate dose levels used in the treatment of hyperactive children, reduced visual vigilance detections made by the squirrel monkey (Figure 1). This effect occurred in a task that re-

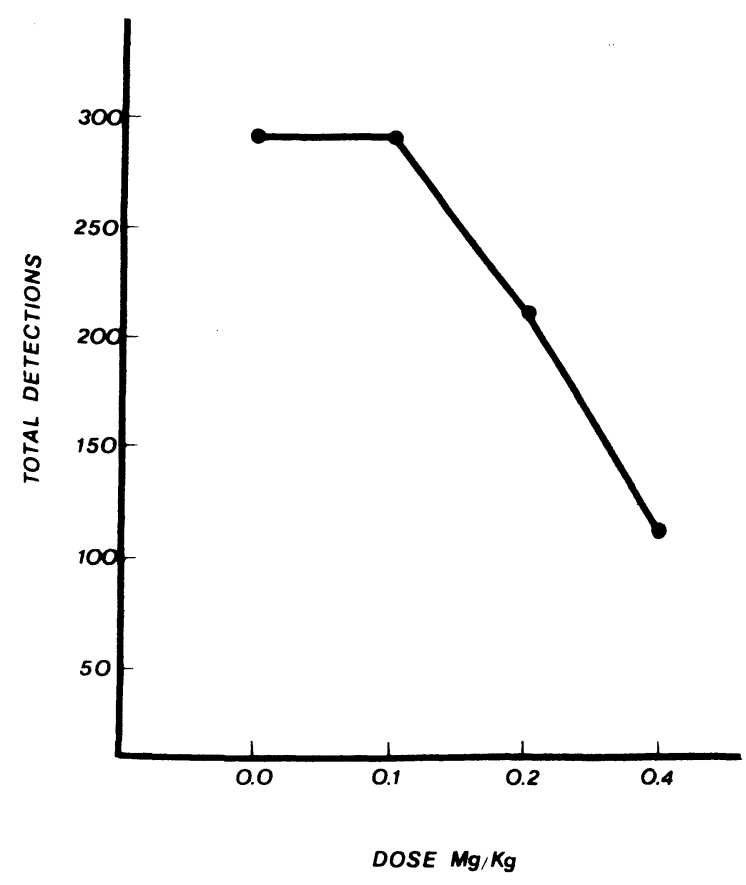

Figure 1. Decrease in total detections as dose of D-amphetamine is increased. 


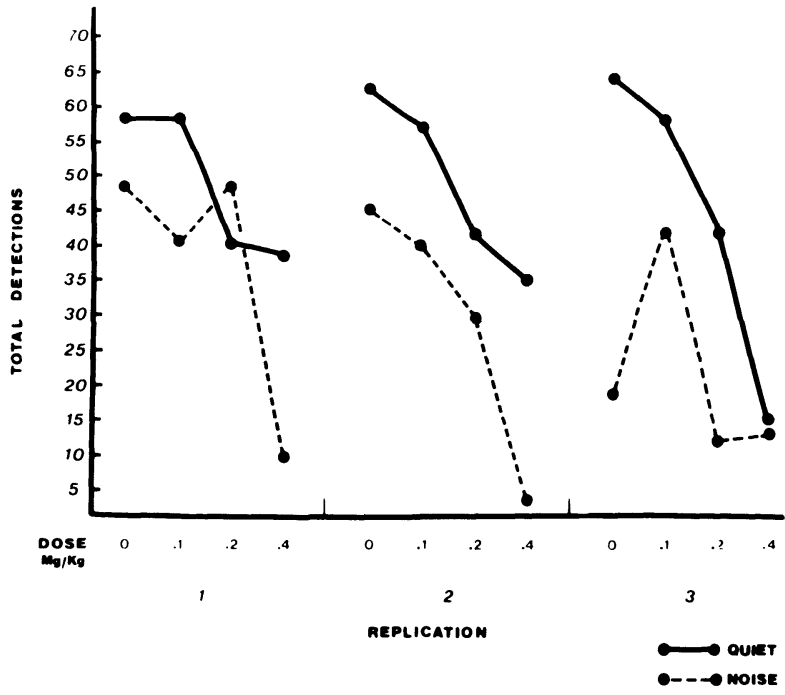

Figure 2. Decrease in detections as an effect of dose, noise-quiet, and replication.

quired constant attention or vigilance. Following Hebb (1955), this result can be taken as indicating a depressed CNS arousal or as a reduction in cortical activity caused by D-amphetamine, which is classified as a CNS stimulant. This effect was not due to the disruption of performance by excessive arousal that would be predicted by the Yerkes-Dodson concept of arousal (Hebb, 1955). It has been shown in a number of experiments that amphetamine decreases motor activity in squirrel monkeys (Isaac \& Troelstrup, 1969; Lowther \& Isaac, 1976). If this is true, it does not follow that the squirrel monkeys in this study were overaroused. Likewise, if the doses of D-amphetamine used in this study caused a high level of arousal, the monkeys should have increased false-alarm lever pushing as the dose was increased. The reduction in false alarms as dose was increased further indicates that the animals were not overaroused. A reduction in CNS arousal due to the effect of D-amphetamine seems to be the most appropriate explanation for the results of this experiment.

Isaac (1960) has reported that white noise, at a level similar to that used in this study, is aversive to the rhesus monkey. Jerison (1957) has reported that human performance declines in visual vigilance tasks accompanied by noise only if the task is complex or demanding. The average training time per animal in this experiment was about 6 months. This prolonged training requirement suggests that the monkeys found this task to be difficult. The results indicate that the animals were distracted and not as responsive to the visual signal in the noise condition as they were in the quiet condition. D-Amphetamine did not interact with the white noise, but did cause an inconsistent rate of detection (Figure 2).

Amphetamine is used therapeutically to treat hyperactivity and attention deficit disorder in children (Quay \& Werry, 1979). Because the stimulant $D$-amphetamine reduces activity and impulsiveness but improves concentration in hyperactive and learning-disabled children, the effect of amphetamine is often called "paradoxical" (Zahn, Rapoport, \&
Thompson, 1980). The present experiment also indicates that the effect of D-amphetamine is not simply excitatory. Amphetamine causes complex behavioral changes in the primate CNS, and its classification as a CNS stimulant appears to be incomplete.

\section{REFERENCES}

DAviEs, D. R., \& TUNE, G. S. (1969). Human vigilance performance. New York: Elsevier.

DElaY, E. R., \& IsAAC, W. (1980). The effects of illumination, damphetamine, and methylphenidate upon vigilance performance of squirrel monkeys. Bulletin of the Psychonomic Society, 15, 203-206.

FrenCH, J. D. (1960). The reticular formation. In J. Field (Ed.), Handbook of physiology: Vol. 1. Neurophysiology: Sec. 6 (pp. 1281-1305). Washington, DC: American Physiological Society.

Gilman, A. G., Goodman, L. S., Rall, T. W., \& Murad, F. (1985). Goodman and Gilman's The pharmacological basis of therapeutics. New York: Macmillan.

Groves, P. M., \& TePPER, J. M. (1983). Neuronal mechanisms of action of amphetamine. In I. Creese (Ed.), Stimulants: Neurochemical, behavioral, and clinical perspectives (pp. 81-129). New York: Raven Press.

HeBs, D. O. (1955). Drives and the C.N.S. (conceptual nervous system). Psychological Review, 62, 243-253.

Hershkovitz, P. (1984). Taxonomy of squirrel monkeys genus Saimiri (Cebidae platrrhine): A preliminary report with description of hitherto unnamed form. American Journal of Primatology, 7, 155-209.

IsAAC, W. (1960). Arousal or tonus? In Current concepts in physiological psychology. Symposium conducted at the meeting of The Southern Society for Philosophy and Psychology, New Orleans.

IsAAC, W. (1971). A study of the relationships between the visual system and the effects of d-amphetamine. Physiology \& Behavior, 6, 157-159.

IsaAC, W., \& Troelstrup, R. (1969). Opposite effect of illumination and d-amphetamine upon activity in the squirrel monkey (Saimiri) and owl monkey (Aotes). Psychopharmacologia, 15, 260-264.

JERISON, H. J. (1957). Performance on a simple vigilance task in noise and quiet. Journal of the Acoustical Society of America, 29, 1163-1165.

LiNDSLEY, D. B. (1958). The reticular activating system and perceptual integration. In H. H. Jasper, L. D. Proctor, W. C. Noshay, \& R. T. Costello (Eds.), Henry Ford Hospital Symposium: Reticular formation of the brain (p. 513). Boston: Little, Brown.

LOWTHER, W. R., \& ISAAC, W. (1976). The effects of d-amphetamine and illumination on behaviors of the squirrel monkey. Psychopharmacology, 50, 231-235.

QUAY, H. C., \& Werry, J. S. (Eds.) (1979). Psychopathological disorders of childhood. New York: Wiley.

SQUIRE, D., \& GolDEN, A. (1988, March). Amphetamine and vigilance performance of rats. Paper presented at the Southeastern Psychological Association annual meeting, New Orleans.

TAYLOR, A. N. (1969). The role of the reticular activating system in the regulation of ACTH secretion. Brain Research, 13, 234-246.

ZahN, T. P., Rapoport, J. L., \& Thompson, C. L. (1980). Autonomic and behavioral effects of dextroamphetamine and placebo in normal and hyperactive prepubertal boys. Journal of Abnormal Child Psychology, 8, 145-160.

(Manuscript received September 17, 1990.) 